This is a peer-reviewed, accepted author manuscript of the following article: Martin, A. P., Downing , J., Collins , B., Godman, B., Alfirevic, A., Greenhalgh, K. L., \& Pirmohamed, M. (Accepted/In press). Examining the uptake of predictive BRCA testing in the UK; findings and implications. European Journal of Human Genetics.

\title{
Examining the uptake of predictive BRCA testing in the UK; findings and implications
}

Short running title: Examining uptake of predictive BRCA testing

Authors: Antony P. Martin ${ }^{1,2^{*}}$ Jennifer Downing ${ }^{1,2}$ Brendan Collins $^{3}$ Brian Godman $^{4,5,6}$ Ana Alfirevic ${ }^{1,2}$ ${ }^{\top}$ Karen Lynn Greenhalgh ${ }^{7}{ }^{\llbracket}$ Munir Pirmohamed ${ }^{1,2}$

Toint senior authors.

Institutions: (1) National Institute for Health Research, Collaborations for Leadership in Applied Health Research and Care, North West Coast (NIHR CLAHRC NWC), (2) Wolfson Centre for Personalised Medicine, University of Liverpool (3) Department of Public Health \& Policy, University of Liverpool, (4) Department of Clinical Pharmacology, Karolinska Institute, Stockholm, Sweden , (5) Strathclyde Institute of Pharmacy and Biomedical Sciences, Strathclyde University, Glasgow, UK, (6) Department of Public Health Pharmacy and Management, School of Pharmacy, Sefako Makgatho Health Sciences University, Garankuwa, South Africa, (7) Liverpool Women's Hospital NHS Foundation Trust

\section{Correspondence:}

Dr Antony P. Martin

Wolfson Centre for Personalised Medicine

University of Liverpool, Block A: Waterhouse Buildings,

1-5 Brownlow Street, Liverpool, L69 3GL

apmartin@liv.ac.uk

Conflict of interest: The authors declare that they have no conflict of interest.

Ethical approval: HRA REC 227795/17CAG0183 approved. 
Accepted for publication European Journal of Human Genetics

\section{ABSTRACT}

Predictive $B R C A$ testing is offered to asymptomatic individuals to predict future risk where a variant has been identified in a relative. It is uncertain whether all eligible relatives access testing, and whether this is related to health care inequalities. Our aim was to analyse trends and inequalities in uptake of testing, and identify predictors of testing and time-to-receipt of testing. A database from April 2010 to March 2017 was collated. Multivariate analysis explored individual associations with testing. Predictor variables included gender, $B R C A$ test type, cancer history, Index of Multiple Deprivation (IMD) and education status. To evaluate factors associated with time-to-testing, a Cox proportional-hazards (CP) model was used. Of 779 tests undertaken, $336(43.1 \%)$ were identified with a $B R C A$ variant. A total of $537(68.9 \%)$ were female and in $83.4 \%(387 / 464)$ of probands, predictive testing was received by relatives. Analysis identified inequalities since decreased testing was found when the proband was unaffected by cancer (OR $0.14,95 \%$ CI $0.06-0.33$ ). Median time-to-testing was 390 days (range, 0-7090 days) and the CP model also identified inequalities in the hazard ratio (HR) for testing for people aged $>40$ was higher than for aged $<40$ (HR 1.41, 95\% CI 1.20-1.67) and $B R C A 2$ testing was higher than for $B R C A 1$ testing (HR 1.39, 95\% CI 1.18-1.64). Reduced testing was found when probands were unaffected by cancer and time-to-testing was found to vary by age and $B R C A 1 / 2$ test. Given limited study sample size, further research is recommended to examine inequalities in predictive $B R C A$ testing.

Keywords: Hereditary Breast Ovarian cancer; Equity; Uptake; $B R C A$ testing 


\section{INTRODUCTION}

The risk of developing a cancer exists in all individuals as genetic changes accumulate when cells divide over time. However, this risk can be increased when individuals possess variants in some genes such as the $B R C A$ genes. ${ }^{1-3}$ Both $B R C A 1$ and $B R C A 2$ variants may be inherited from either parent, and this can significantly influence the risk of developing breast cancer, ovarian cancer and prostate cancer. The risk of other cancers including those in the pancreas, stomach, skin, and colon can also be increased. ${ }^{3,4}$

$B R C A 1$ and $B R C A 2$ encode proteins that are essential for the repair of DNA double-strand breaks by homologous recombination (HR). ${ }^{5} B R C A 1$ and $B R C A 2$ belong to a class of tumour suppressor genes and as such, a variant which affects function in either gene may allow cells to grow uncontrollably. The identification of an inherited $B R C A$ variant is thus important as it allows more frequent follow-up and the implementation of cancer prevention strategies. ${ }^{5}$ Diverse approaches exist to identification and management, and may differ dependent on gender, age, family history and existing comorbidities. These include risk-reducing lifestyle changes, therapies and surgical procedures including bilateral mastectomy and/or salpingooophorectomy. ${ }^{6,7}$

$B R C A$ variants are rare and are known to exist in 0.2 to $0.3 \%$ of the general population. ${ }^{1-4}$ However, the child of a person with a $B R C A$ variant has a $50 \%$ chance of inheriting the variant and therefore has an increased risk of developing cancer. ${ }^{8}$ It has been reported that inherited $B R C A$ variants confer a $39 \%$ to $85 \%$ lifetime risk of breast cancer $(\mathrm{BC})$ and an $11 \%$ to $62 \%$ lifetime risk of ovarian cancer. ${ }^{9}$ Males with $B R C A 1$ variant have a lifetime $\mathrm{BC}$ risk of $1-5 \%$ and $2-3 \%$ risk of pancreatic cancer. Males with a $B R C A 2$ variant have a lifetime $\mathrm{BC}$ risk of 5$10 \%, 15-25 \%$ risk of prostate cancer, and a $3-5 \%$ risk of melanoma. ${ }^{10,11}$ Consequently, 
predictive $B R C A$ testing should be offered in an asymptomatic individual to predict future risk where a variant has been identified in a family relative, i.e. a proband.

In England and Wales, the National Institute for Health and Care Excellence (NICE) published updated guidelines for Familial Breast Cancer Testing [CG164]. ${ }^{12}$ NICE recommended that testing should be conducted in patients with ovarian or breast cancer where the combined probability of identifying a $B R C A 1$ or $B R C A 2$ variant is greater or equal to $10 \% .^{12}$ Importantly, NICE (CG164 1.3.6) also recommended testing in asymptomatic relatives where a $B R C A$ variant was identified within their family. Family members may then be recommended for testing for the same specific variant to inform future risk. ${ }^{12,13}$

Despite marked benefits from $B R C A$ testing and risk reduction strategies in the form of decreased cancer incidence, morbidity, and mortality, it has been reported in some settings that a lower proportion of women with high-risk histories undergo $B R C A$ testing. ${ }^{14,15}$ Further, it has been reported that women from families with few female relatives are unlikely to recognise their $B R C A$ carrier risk until they develop cancer. ${ }^{9}$

A study by Holloway et al. $(2008)^{16}$ found evidence that deprivation was also associated with lower attendance to genetic services in Scottish patients with a family history of breast cancer. Other studies predominantly from the USA have found that women with lower education attainment and from minority ethnic groups were less willing to undergo testing, less likely to be referred for counselling and less likely to undergo $B R C A$ testing. ${ }^{17-22}$ To date few studies have explored how men manage $B R C A$-related cancer risks, but men seem to be less aware of genetic testing than females. ${ }^{19,23-25}$ As such, concern has been raised that males at risk of $B R C A$-related cancer risk are insufficiently tested. ${ }^{11}$

$B R C A$ test results may have wider implications for relatives and may inform future health care needs. However, it is uncertain whether all relatives who are eligible for predictive $B R C A$ 
testing access this information in a timely manner and there is concern that some people delay testing. Delay to predictive $B R C A$ testing may have implications for the subsequent management of health risk. Research is therefore needed to assess whether some groups delay accessing testing. ${ }^{26}$ Despite the fact that healthcare systems such as the UK NHS are free at the point of delivery, it is possible that certain health services may be unavailable, unacceptable and not accessed in some populations groups, such as in ethnic minorities and groups with lower education attainment. ${ }^{15}$

To date, little research has analysed the implementation of predictive $B R C A$ testing in the UK. ${ }^{12}$ Consequently, the aims of this study were to analyse trends and inequalities in the uptake of predictive $B R C A$ testing. The primary objective was to examine predictors of BRCA testing, with the secondary objective being to analyse time to receipt of predictive $B R C A$ testing.

\section{METHODS}

\section{Study population and data sources}

Retrospective routinely collected hospital data from the Merseyside and Cheshire Regional Genetic Service (RGS) hosted by Liverpool Women's NHS Foundation Trust were analysed. We chose this region for this study as the RGS is responsible for care in Merseyside and Cheshire (with the exception of boundary areas) serving a catchment area of $\sim 2.4$ million people with a diverse population including areas of deprivation. Data were collected for individuals aged $\geq 18$ years old from April 2010 and March 2017 who received predictive $B R C A$ testing.

Predictive $B R C A$ testing is recommended in asymptomatic relatives where a $B R C A$ variant was identified within a family member. Other family members may then be recommended for testing for the same specific variant to inform future risk. $B R C A$ testing describes DNA 
sequencing analysis of both $B R C A 1$ and $B R C A 2$ genes and comparing that analysis to the reference sequence. Testing also included MLPA dosage analysis to exclude the presence of whole deletion or duplication. The method of sequence analysis has changed over the timeframe of the study from bi-directional fluorescent sequencing in 2010 to long range PCR and next generation sequencing on Illumina MiSeq (minimum 100x coverage) using an inhouse variant calling bioinformatic pipeline with sanger confirmation of variants called or areas of the gene with less than 100x coverage.

\section{Measures}

Baseline characteristics were summarised for people who received predictive $B R C A$ testing, which included age, gender, which $B R C A$ gene was tested and whether a variant which affects function was identified. In addition, the number of predictive $B R C A$ testing provided following proband testing and the average number of days from proband testing to predictive $B R C A$ testing in relatives was examined. For all the recipients of predictive $B R C A$ testing at Merseyside and Cheshire RGS, Lower Layer Super Output Area (LSOA) of residence was mapped to an Index of Multiple Deprivation (IMD) quintile. ${ }^{27}$

LSOAs are the smallest geographical units for which IMD scores are available. From the 2011 census, there were 32,844 LSOAs used in the 2015 Indices of Deprivation in England. ${ }^{27}$ Each LSOA contains a small cluster of postcodes with comparable characteristics with a mean population of $\sim 1500$ people. LSOAs are not necessarily similar in terms of sociodemographic structure, although often they border natural geographical features such as roads and rail lines. LSOAs were mapped onto IMD quintile which combines seven indicators (income, employment, health deprivation and disability, education, skills and training, barriers to housing and services, crime, and living environment), into a single-deprivation index. ${ }^{27}$ Data 
for patients registered at an address outside of England were excluded from the deprivation analysis as information could be not applied for the same index.

\section{Statistical analyses}

\section{Examining predictive $B R C A$ testing in family members}

To examine the implementation of predictive $B R C A$ testing, the IMD score for each member of the catchment population was defined based on their respective LSOA residency. Deprivation scores were then divided into national deprivation quintiles for the catchment population.

As mentioned, it is uncertain whether all family members who are eligible for predictive $B R C A$ testing following proband testing go on to access testing. As such, a univariate analysis was conducted to explore individual associations with predictive $B R C A$ testing of relatives for a family variant to see whether differences in uptake may exist. Predictor variables included: gender, type of $B R C A$ test received, cancer history, socioeconomic status represented by IMD and Education status, represented by the IMD domains for education, skills and training. A multivariate logistic regression analysis included both clinically and statistically significant predictors was subsequently undertaken ( $\mathrm{P}<0.1$ on univariate analysis). All predictors were included in the multivariate model and were removed in a backward stepwise process if they were not statistically significant predictors and if they confounded relationships between other variables in the model (defined as a change in the odds ratio of at least $10 \%$ ).

\section{Predictors of time from proband BRCA testing to predictive $B R C A$ testing}

As mentioned, an exploration of predictors of time from proband BRCA testing to receipt of $B R C A$ testing by family relatives was undertaken. The distribution of time to $B R C A$ testing was 
estimated using the Kaplan-Meier method by gender, age, gene, test result, IMD and education and skills rank. ${ }^{28}$

To evaluate significant factors associated with time to $B R C A$ testing, the Cox proportionalhazards (CP) model was used, incorporating variance adjustment for observations clustered by family relation. ${ }^{28}$ The $\mathrm{CP}$ hazards model is semi-parametric as no assumptions are made about the shape of the baseline hazard function. Three important assumptions for a CP hazards model were made. Firstly, survival times between individuals in the sample are distinct; secondly, there was a multiplicative relationship between the predictors and the hazard. Thirdly, that there was a constant hazard ratio over time (proportional hazards assumption). ${ }^{29}$

Factors significant on univariate analysis were included in the Cox regression multivariable analysis, which was used to compute hazard ratios (HRs) with $95 \%$ confidence intervals to identify independent prognostic factors for $B R C A$ testing using a forward selection variableselection process (in the context of a small sample size, $\mathrm{P}<0.1$ was considered significant). All analyses were conducted using STATA 16.0 (STAT Corp., College Station, TX).

\section{RESULTS}

Between April 2010 and March 2017, 779 predictive $B R C A$ tests were undertaken in the region, of whom $336(43.1 \%)$ had a $B R C A$ variant which affects function. A general upward trend was identified and is described in Figure 1. 
Figure 1 - Number of proband and predictive $B R C A$ tests conducted per year

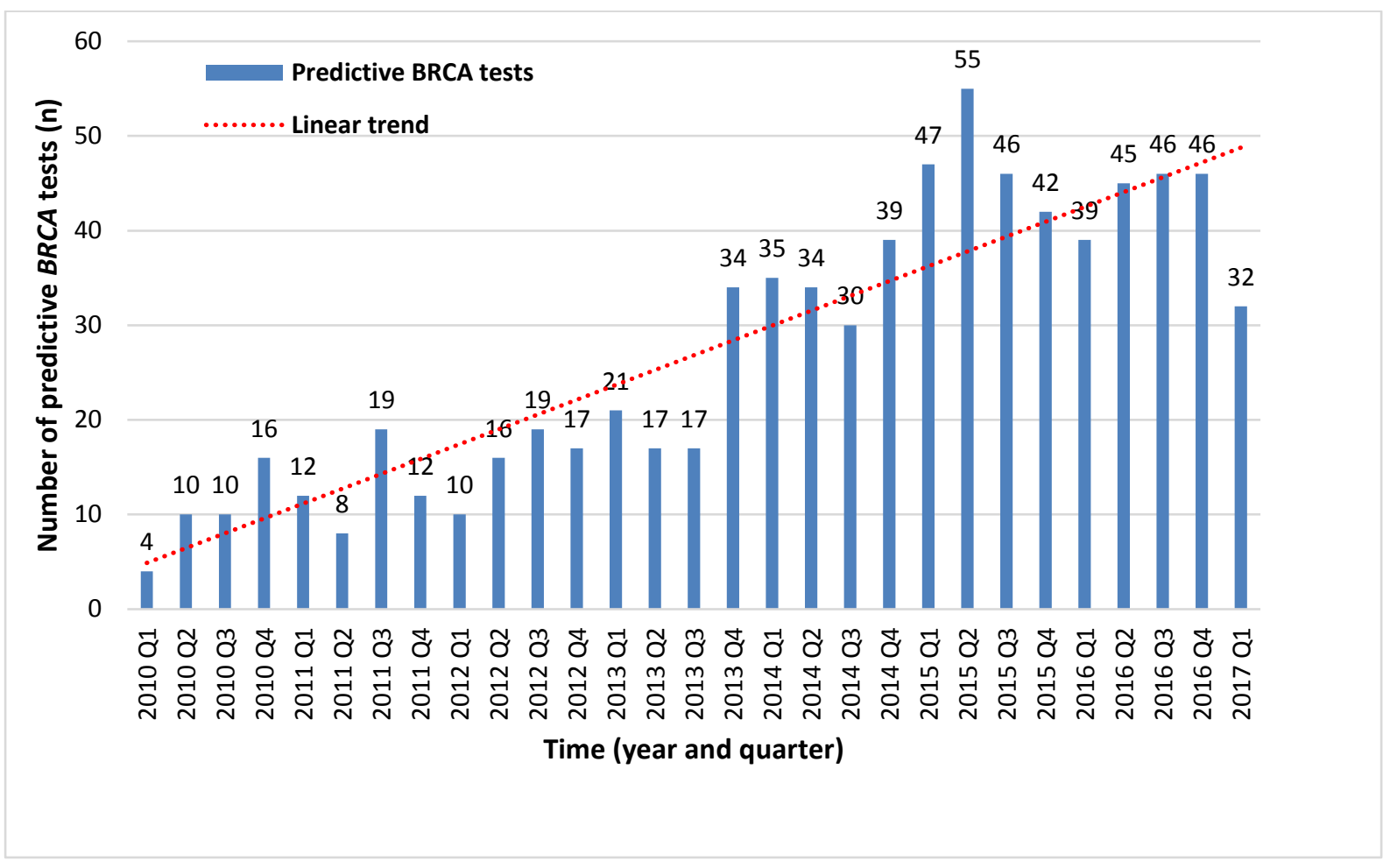

Patient baseline characteristics are described in Table 1. Female patients made up 537 (68.9\%) of the study population and the mean age at the time of the $B R C A$ test was 46.4 years (SD 15.2; range $18-87$ years). Data for $4.9 \%(38 / 779)$ of patients registered at an address outside of England were excluded from the deprivation analysis. Of the total study population, 321 (41.2\%) received a $B R C A 1$ test, $457(58.7 \%)$ received a $B R C A 2$ test, and one patient received both a BRCA1 and BRCA2 test.

Table 1 - Baseline study population demographics

\begin{tabular}{|c|c|c|c|}
\hline & $\begin{array}{l}\text { Total } \\
\text { study } \\
\text { populati } \\
\text { on, n } \\
(\%)\end{array}$ & $\begin{array}{l}\% / S \\
D\end{array}$ & $\begin{array}{l}\text { Cheshire \& } \\
\text { Merseyside } \\
\text { population, } \\
\text { n }(\%)\end{array}$ \\
\hline Number & 779 & & $\begin{array}{l}2454534 \\
(100)\end{array}$ \\
\hline Gender Female & 537 & 68.9 & $\begin{array}{l}1,255,031 \\
(51.1)\end{array}$ \\
\hline Male & 242 & 31.1 & $\begin{array}{l}1,199,503 \\
(48.9)\end{array}$ \\
\hline Age (SD) & 46.4 & 15.2 & $41.1(-)$ \\
\hline \multicolumn{4}{|l|}{ Gene tested } \\
\hline$B R C A 1$ & 321 & 41.2 & \\
\hline
\end{tabular}




\begin{tabular}{|c|c|c|c|}
\hline$B R C A 2$ & 457 & 58.7 & \\
\hline$B R C A 1$ and $B R C A 2$ & 1 & 0.1 & \\
\hline \multicolumn{4}{|l|}{ Genetic test result } \\
\hline No variant which affects function identified* & 443 & 56.9 & \\
\hline Variant which affects function identified & 336 & 43.1 & \\
\hline \multicolumn{4}{|l|}{ Index of Multiple Deprivation (IMD) } \\
\hline 1 (most deprived) & 253 & 34.1 & $\begin{array}{l}797,326 \\
(33.0)\end{array}$ \\
\hline 2 & 122 & 16.5 & $\begin{array}{l}373,335 \\
(15.5)\end{array}$ \\
\hline 3 & 117 & 15.8 & $\begin{array}{l}377,279 \\
(15.6)\end{array}$ \\
\hline 4 & 141 & 19.0 & $\begin{array}{l}418,590 \\
(17.3)\end{array}$ \\
\hline 5 (least deprived) & 108 & 14.6 & $\begin{array}{l}447,723 \\
(18.5)\end{array}$ \\
\hline Unknown & 38 & & \\
\hline \multicolumn{4}{|l|}{ Education and skills rank } \\
\hline 1 (lowest rank) & 241 & 32.5 & $\begin{array}{l}646235 \\
(26.8)\end{array}$ \\
\hline 2 & 136 & 18.4 & $\begin{array}{l}374609 \\
(15.5)\end{array}$ \\
\hline 3 & 120 & 16.2 & $\begin{array}{l}377554 \\
(15.6)\end{array}$ \\
\hline 4 & 107 & 14.4 & $\begin{array}{l}389920 \\
(16.2)\end{array}$ \\
\hline 5 (highest rank) & 137 & 18.5 & $\begin{array}{l}625935 \\
(25.9)\end{array}$ \\
\hline Unknown & 38 & & \\
\hline $\begin{array}{l}\text { Average days (SD) to family testing following the identification } \\
\text { of proband variant }\end{array}$ & 1008 & 1292 & \\
\hline $\begin{array}{l}\text { Median days to family testing following the identification of } \\
\text { proband variant }\end{array}$ & 390 & & \\
\hline
\end{tabular}

Descriptive analysis of number of predictive BRCA tests received following proband testing

Predictive $B R C A$ testing describes the receipt of a $B R C A$ test in an asymptomatic person to predict the future risk of developing cancer where a variant which affects function was found within a BRCA gene in a family member (proband). In 83.4\% (387/464) of probands (index patients), subsequent predictive BRCA testing was received by family relatives. Within the observation period, the amount of predictive $B R C A$ testing in relatives varied with most families receiving one test and some receiving more than five predictive $B R C A$ tests as shown in Figure 2. Of 779 relatives who underwent predictive $B R C A$ testing, it was unknown how 
many of these relatives corresponded to the 1393 probands who met the criteria for $B R C A$ testing as there was no direct link between the two datasets.

Figure 2 - Number of predictive $B R C A$ tests received per family

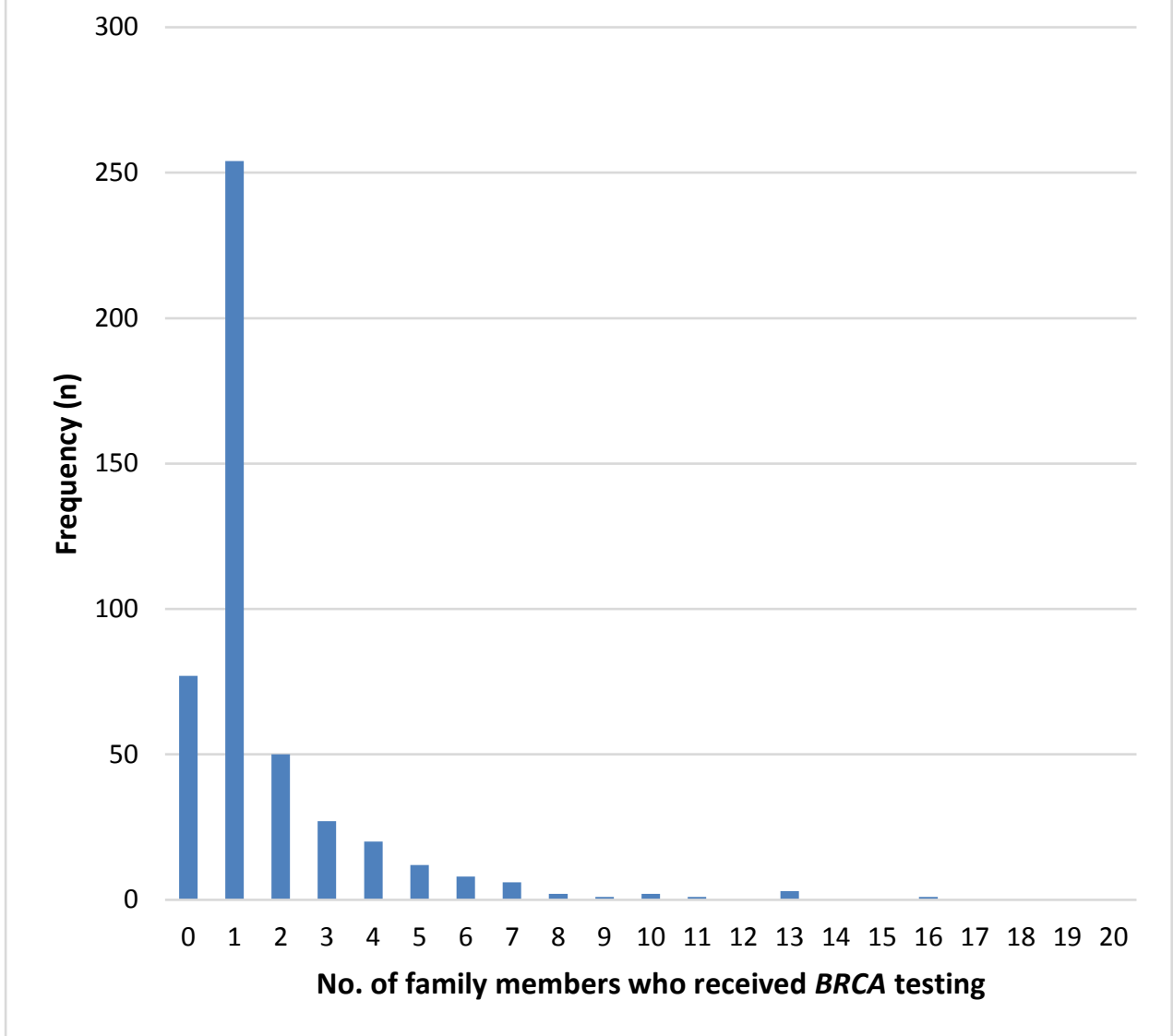

Note: This histogram indicates the number of family members by proband that received $B R C A$ testing

Multivariate logistic regression to explore predictors of predictive BRCA testing following proband testing

Non-complete cases were dropped from the analysis, which reduced the sample size from 464 observations to 166 observations (of 7 variables). Of the 166 probands, $97.0 \%(161 / 166)$ were female, 51.2\% (85/166) and 48.2\% (80/166) had undergone BRCA1 and BRCA2 testing, $60.8 \%$ $(101 / 166)$ had breast cancer, $19.3 \%(32 / 166)$ had ovarian cancer, 6.6\% (11/166) had other cancers and $13.3 \%(22 / 166)$ were unaffected by cancer. Of 166 probands, 58.4\% $(97 / 166)$ and 41.6\% (69/166) were from an LSOA defined as disadvantaged and advantaged by IMD, respectively. Further, 50.6\% (84/161) and 49.4\% (82/161) were from an LSOA defined as 
lower education and a higher level of education (based on education, skills and training assignment).

In multivariate logistic analysis, gene tested and cancer type were found to be associated with family testing at 10\% level of significance (Table 2). Independent variables including sex, IMD and education were not found to be significant predictors. Increased likelihood of family testing was identified in probands tested for $B R C A 2$ status; however, only a weak non-significant association was identified $(\mathrm{P}=0.086)$. Decreased family testing was seen when the proband was unaffected by cancer (OR $0.14,95 \%$ CI 0.06 to 0.33$)(\mathrm{P}<0.001)$. In the multivariate regression model, no significant interactions were identified which may have been in part due to small sample size.

Table 2 - Variables associated with $B R C A$ testing of relatives for a family variant in $B R C A$-positive probands

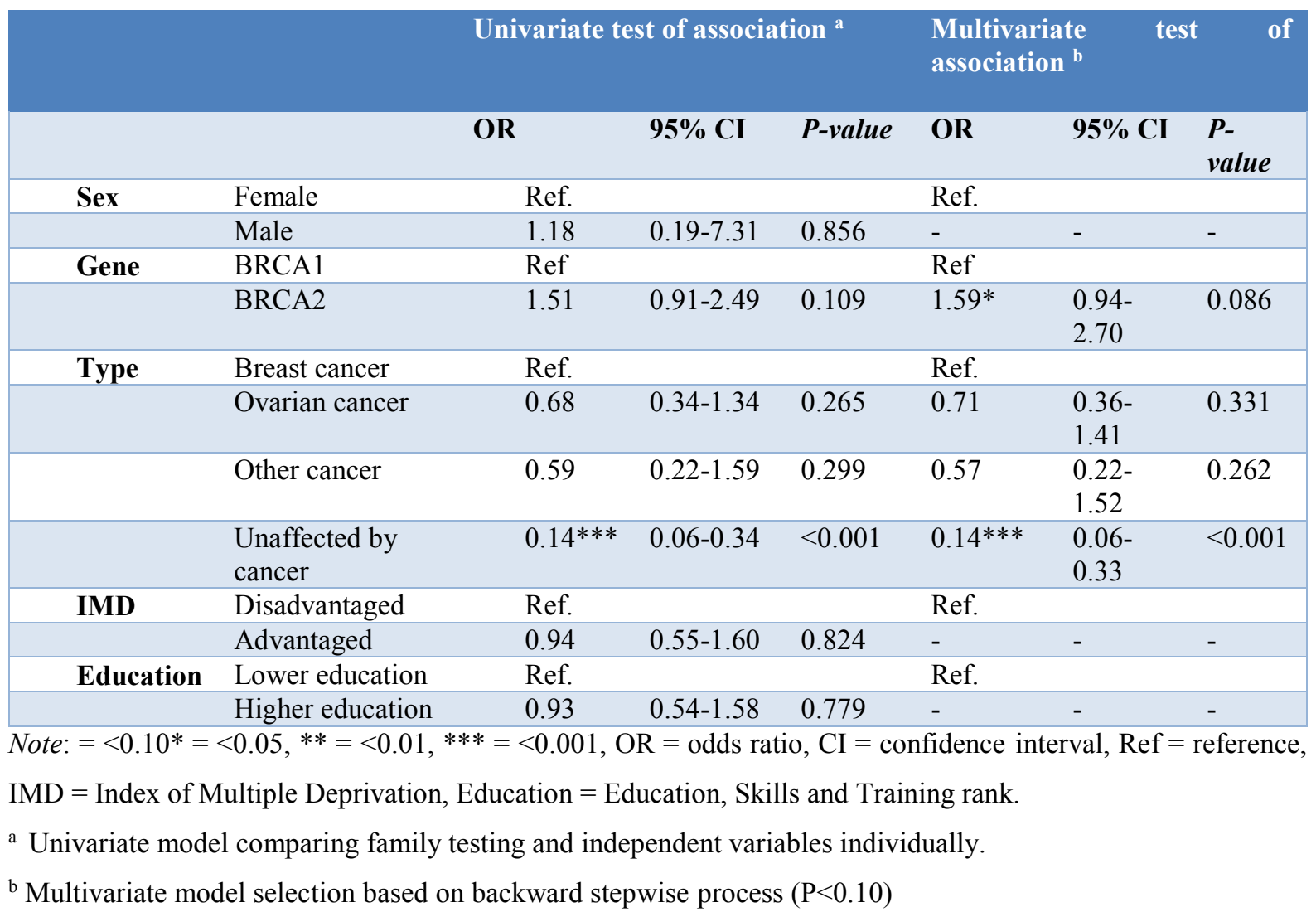




\section{Descriptive analysis of time from proband BRCA testing to receipt of predictive BRCA testing}

Figure 3 illustrates the time from proband $B R C A$ testing to receipt of predictive $B R C A$ testing. Mean time to testing was 1008 (SD 1292) days with a median of 390 days (range, 0 to 7090 days). Proband BRCA testing was first offered to some patients in 1997 and therefore, there was a wide distribution in time to predictive $B R C A$ testing. Records of predictive $B R C A$ testing occurred between January 2010 and September 2017.

\section{Figure 3 - Time from receipt of proband $B R C A$ test to predictive $B R C A$ testing}

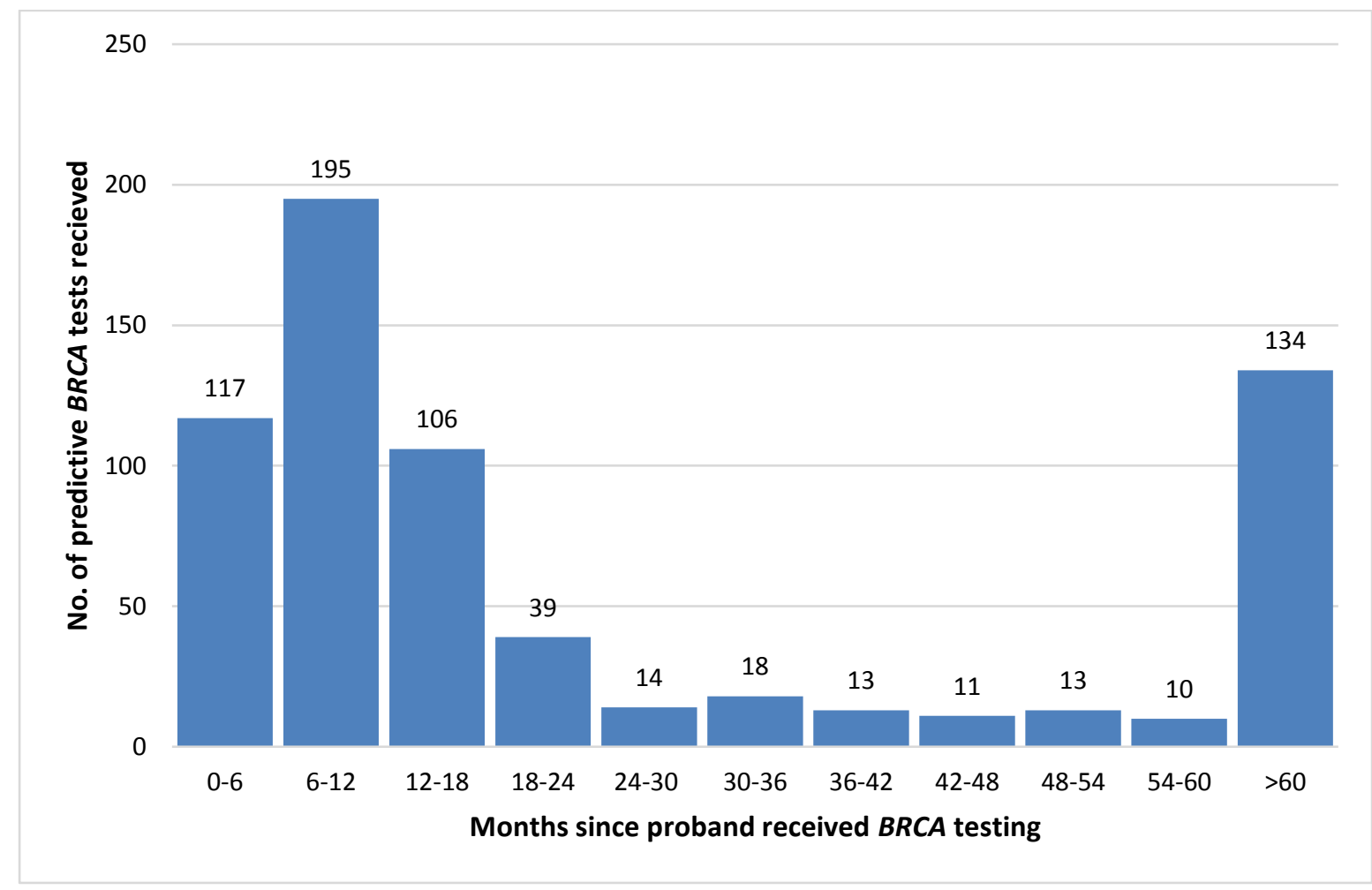

In supplemental Figure 1, Kaplan-Meier (KM) plots illustrate variation in time to predictive $B R C A$ testing by gene tested, test result, gender, age, IMD and education. Based on the KM time to event plot, all illustrated a relatively quick uptake of predictive $B R C A$ testing for the first $50 \%$ of relatives who received testing. In the KM plots for BRCA gene (A), age (D) and IMD (E), there appeared subgroup disparities in time to uptake of testing. 
Cox proportional hazards regression to examine predictors of time to predictive BRCA testing

As described in Table 3, in univariate analysis, people aged $>40$ were more likely to receive predictive $B R C A$ testing in less time (HR 1.39, 95\% CI 1.19 to 1.64$)(\mathrm{P}<0.001)$. Relatives of probands that were tested for $B R C A 2$ were more likely to receive predictive $B R C A$ testing in less time in comparison to relatives of probands who underwent $B R C A 1$ testing (HR 1.40, 95\% CI 1.19 to 1.64) $(\mathrm{P}<0.001)$. In addition, predictive BRCA testing in the least deprived quintile (Q5) was found to be quicker than in the most deprived quintile (Q1) (HR 1.30, 95\% CI 1.01 to 1.67$)(\mathrm{P}=0.044)$.

Table 3 - Univariate and Cox regression multivariate analysis for time to $B R C A$ testing

\begin{tabular}{|c|c|c|c|c|c|c|c|}
\hline \multirow{2}{*}{ Variable } & & \multicolumn{3}{|c|}{ Univariate analysis } & \multicolumn{3}{|c|}{$\begin{array}{l}\text { Cox regression multivariate } \\
\text { analysis }\end{array}$} \\
\hline & & HR & $95 \% \mathrm{CI}$ & p-value & HR & $95 \% \mathrm{CI}$ & p-value \\
\hline \multirow[t]{2}{*}{ Sex } & Female & Ref. & & & Ref. & & \\
\hline & Male & 0.96 & $0.82-1.13$ & 0.634 & - & - & - \\
\hline \multirow[t]{2}{*}{ Age } & $<40$ years & Ref. & & & Ref. & & \\
\hline & $>40$ years & $1.39 * * *$ & $1.19-1.64$ & $<0.001$ & $1.41 * * *$ & $1.20-1.67$ & $<0.001$ \\
\hline \multirow[t]{3}{*}{ Gene } & BRCA1 & Ref & & & Ref & & \\
\hline & BRCA2 & $1.40 * * *$ & $1.19-1.64$ & $<0.001$ & $1.39 * * *$ & $1.18-1.64$ & $<0.001$ \\
\hline & BRCA1\&2 & 3.17 & $0.44-22.69$ & 0.250 & & & \\
\hline \multirow{2}{*}{ Result } & Negative & Ref. & & & Ref. & & \\
\hline & Positive & 0.94 & $0.81-1.10$ & 0.442 & - & - & - \\
\hline \multirow{5}{*}{$\begin{array}{l}\text { Index of } \\
\text { Multiple } \\
\text { Deprivation }\end{array}$} & 1 (most deprived) & Ref. & & & Ref. & & \\
\hline & 2 & 0.94 & $0.75-1.18$ & 0.572 & 0.84 & $0.67-1.06$ & 0.140 \\
\hline & 3 & 1.11 & $0.87-1.40$ & 0.398 & 1.02 & $0.80-1.29$ & 0.895 \\
\hline & 4 & 0.84 & $0.67-1.05$ & 0.129 & $0.78 * *$ & $0.62-0.98$ & 0.033 \\
\hline & 5 (least deprived) & $1.30 * *$ & $1.01-1.67$ & 0.044 & $1.26^{*}$ & $0.98-1.62$ & 0.075 \\
\hline \multirow{5}{*}{$\begin{array}{l}\text { Education } \\
\text { and skills } \\
\text { rank }\end{array}$} & 1 (lowest rank) & Ref. & & & Ref. & & \\
\hline & 2 & 0.92 & $0.72-1.16$ & 0.475 & - & - & - \\
\hline & 3 & 0.93 & $0.73-1.18$ & 0.538 & - & - & - \\
\hline & 4 & 0.99 & $0.78-1.27$ & 0.962 & - & - & - \\
\hline & 5 (highest rank) & 0.88 & $0.71-1.11$ & 0.281 & - & - & - \\
\hline
\end{tabular}

Note: $.=<0.10^{*}=<0.05, * *=<0.01, * * *=<0.001, \mathrm{HR}=$ hazard ratio, $\mathrm{CI}=$ confidence interval, $\mathrm{Ref}=$ reference, $\mathrm{IMD}=$ Index of Multiple Deprivation, Education = Education, Skills and Training rank.

As presented in Table 3, CP hazards regression examined how groups differ in time to $B R C A$ testing and adjusted for predictors included in the model. As before, non-complete cases were dropped from the analysis, which reduced the sample size from 669 observations to 636 observations. Multiple imputation methods were precluded as missing data were assumed to 
be missing not at random. The recommended method to handle tied failures (Breslow) was implemented and other methods included Efron, Exact Marginal Likelihood and Exact Partial Likelihood, which provided similar results. ${ }^{30}$

The regression indicated that the likelihood of $B R C A$ testing for people aged $>40$ was significantly higher than for people aged $<40$ years (HR 1.41, 95\% CI 1.20 to 1.67$)(\mathrm{P}<0.001)$. A further exploration of the data found that 29 people who received $B R C A$ testing were between 18 to 21 years and 'waited' an average of 1539 days (SD 1547) which was considerably higher than the average wait for the overall population of 1008 days (SD 1292). This further exploration was undertaken as younger populations may have been ineligible at time of proband testing in some cases.

$B R C A 2$ testing was found to be significantly higher than $B R C A 1$ testing (HR 1.39, 95\% CI 1.18 to 1.64$)(\mathrm{P}<0.001)$. In addition, the hazard ratio for predictive $B R C A$ testing in the least deprived quintile (Q5) was found to be higher than the most deprived quintile (Q1) (HR 1.26 95\% CI 0.98 to 1.68$)(\mathrm{P}=0.075)$, although this was not significant at the 5\% level. However, the inverse was found when comparing the fourth quintile to be less and this was significant (HR $0.7895 \%$ CI 0.62 to 0.98$)(\mathrm{P}=0.033)$. Other variables were not included in the model as they were not found to be significant in the univariate analysis.

\section{DISCUSSION}

In hereditary cancer syndromes, a clinically important and cost-effective method to potentially decrease cancer incidence with chemoprevention and risk-reducing surgery by targeting predictive $B R C A$ gene testing toward families with a known variant. ${ }^{31}$ Our research examined sociodemographic information of probands to examine predictors of $B R C A$ testing in family relatives in the UK. Rates of predictive $B R C A$ testing were found to increase over time; however, uptake by subgroup remains uncertain. Differing rates of predictive $B R C A$ testing 
require additional research to examine whether these findings reflect differing health needs for predictive $B R C A$ testing or whether this reflects an inequality in access.

We found that predictive $B R C A$ testing was more likely in families if probands were tested for a $B R C A 2$ variant. It is uncertain what the reason would be for this difference by gene affected. The results also showed that predictive $B R C A$ testing was less likely to be received by family relatives if probands were unaffected by cancer. This is an intuitive finding as the benefit/risk ratio for testing in relatives would be lower than for family relatives of probands who were affected by cancer. One study also found that uptake of risk-reducing surgeries was less common in carriers of $B R C A$ variants which affect function if first or second-degree family relatives had not died from cancer. ${ }^{32}$

In lower socioeconomic groups and in different multicultural settings, uptake may be even lower than expected. Further, we found that in many family relatives of probands, predictive $B R C A$ testing is delayed, some for several years after the proband learns that they carry a $B R C A$ variant. Additional analyses examined the association between time since proband testing to predictive $B R C A$ testing and characteristics of family relatives. It was found that the median time to testing was 390 days with wide variability. It was found that the expected hazard was 1.41 times higher for predictive $B R C A$ testing in people aged $>40$ years than people aged $<40$ years. This could be a consequence of surgical recommendations (e.g. removal of ovaries) for preventative surgery in females following ages for childbearing. ${ }^{33}$ From our data, it is unclear the proportion of younger people who were eligible for testing received information from their proband, attended counselling and refused or delayed predictive $B R C A$ testing. Previous research has highlighted the need for more tailoring of predictive test counselling to the needs of young people..$^{34,35}$ 
Potentially, the age disparity may be because younger populations were more likely to be eligible for testing as second- or third-degrees relatives. Within this dataset it was not possible to know whether the relative which received predictive $B R C A$ testing was a first-degree relative (e.g. parent or sibling), second-degree relative (e.g. grandparent or aunt or uncle) or thirddegree relative (e.g. cousin). A study by Healey et al. (2017) found that larger, more geographically diverse families have greater difficulty in disseminating $B R C A$ variant risk information with relatives. ${ }^{36}$ The study found that at least one relative had not been informed in $52.7 \%$ of families, $4.3 \%$ were first-degree, $27 \%$ were second-degree and $62 \%$ were thirddegree relatives. ${ }^{36}$

Interestingly, the expected hazard was 1.31 times higher for predictive $B R C A 2$ testing than predictive $B R C A 1$ testing. However, the reason for this disparity is unknown and will be the subject of further research. The data also showed that the expected hazard was 1.26 times higher for predictive $B R C A$ testing in populations from the least deprived IMD quintile (Q5) compared to the most deprived quintile (Q1). These findings support an association of effect that merit further research to examine the rationale behind disparities in testing. Despite testing being free at point of delivery in the UK, the impact of free testing and free counselling may not be sufficient to remove all barriers to access. It may be that relatives with lower socioeconomic status may not be able to afford time from their work or have reliable childcare available to allow time to attend appointments. Further research is also needed to explore uptake of $B R C A$ testing between diverse ethnic groups and also to explore differences from within groups. A study by Fehniger et al (2013) found that African American and Asian/Pacific Islander patients were less likely to disclose their results to their relatives. ${ }^{37}$

$B R C A$ testing became clinically available in the mid-1990's and historically, those who took up the test, were females affected by cancer. However, today, there are many genetic 
counselling programs, which commonly test unaffected relatives. While probands may have typically received genetic counselling in a medical setting, relatives may often be informed of the implications of $B R C A$ testing by the proband themselves. However sometimes information about $B R C A$ status may not be shared by probands to other family members at risk. Consequently, as genetic testing programmes expand, it is anticipated that improved mechanisms to facilitate communication in families are needed following the identification of $B R C A$ variants. ${ }^{38,39}$ It has been argued that given the utility of $B R C A$ testing information, mandatory guidelines should be created to communicate risk information. ${ }^{40}$ Further, it has been argued that it is unacceptable for such information to be withheld where effective prevention is available and effective treatments exist. ${ }^{40,41}$

There is an ongoing debate related to issues of confidentiality, right not to know and duty to warn. Such complex ethical and legal questions may reduce changes to current policies. Moreover, insurance issues should be considered as the outcomes may have financial implications for the whole family in the future. ${ }^{40,42-45}$ As such, support programmes for probands have been proposed which include the provision of additional counselling, training and educational materials such as information leaflets and online information. Importantly, the impact of "family letters" with concise information provided by the healthcare professionals (HCP) has been questioned. Alternative and supplementary methods of communication are proposed and further consideration for direct contact by HCPs has also been suggested. ${ }^{40,46}$ One possible alternative method would be to permit the HCP to contact other family members at risk via telephone based on the information shared by the proband. Alternatively, there have been high-profile appeals for population-wide $B R C A$ screening to be offered to all females aged 30 and over. ${ }^{14,47,48}$ However, careful consideration of the potential limitations of populationwide screening in the context of the associated risks, benefits and costs is needed. Further, it is uncertain if population-wide screening would mitigate differential uptake of testing. 
An important limitation of the analysis of potential health care disparities was that relatives only had access to $B R C A$ testing if probands had access to testing and were tested. Data were not collected for probands who could not access testing or refused testing. Another limitation was that there was a high level of missing data relating to the proband testing (approximately 25\%) conducted outside of Merseyside and Cheshire RGS. We highlight the need for a national joined dataset for such research. As the original dataset was not designed for research, some core information should as age, gender and type of cancer was not routinely collected. Data were assumed missing not at random and therefore multiple imputation methods were precluded. Further, the number of predictive $B R C A$ tests which were received outside of the NHS is uncertain. An additional limitation relates to the insensitivity of IMD matched to each LSOA as within each LSOA there may be significant variation in terms of deprivation. ${ }^{27}$ Additionally, recorded data might be subject to recording errors or adjudication errors, and further, the reliability of the coding of $B R C A$ tests might have changed over time. However, there was no evidence of changes in treatment coding during the study. Despite these limitations, we believe the study and its findings provide guidance for future studies as more data becomes available.

\section{CONCLUSIONS}

In conclusion, at least one family relative of $83.4 \%$ of probands was tested. This study identified populations which may be less likely to receive $B R C A$ testing although further research is recommended. The analysis found that females and family members of probands affected by cancer were more likely to undergo testing. In addition, families of probands were found to be more likely to undergo predictive $B R C A$ testing sooner if the proband was older and if the proband had a $B R C A 2$ variant. As discussed, there is currently no procedure which guarantees that relatives of probands receive timely information about their $B R C A$ status. 
The issue is becoming increasingly important with the mainstreaming of $B R C A$ testing in clinical oncology. Furthermore, as genetic testing for cancer predisposition becomes more accepted and available, it is important to ensure the communication of genetic testing results and subsequent family testing translates to ensure horizontal equity. Future studies should examine the most effective ways to facilitate communication of proband $B R C A$ results to ensure underserved populations realize the potential benefits of genetic testing for cancer predisposition.

\section{ACKNOWLEDGEMENTS}

This study was supported by the National Institute for Health Research Collaboration for Leadership in Applied Health Research and Care North West Coast (NIHR CLAHRC NWC). The investigators were solely responsible for the content and the decision to submit the manuscript for publication. The funding source had no role in the selection, critical appraisal, or synthesis of evidence. The views expressed are those of the authors and not necessarily those of the NHS, the NIHR or the Department of Health.

\section{AUTHOR CONTRIBUTIONS}

$\mathrm{AM}, \mathrm{JD}, \mathrm{BC}, \mathrm{AA}, \mathrm{MP}$ and KLG were involved with the conception and design of the study. AM, JD, MP and KLG were involved with acquisition of data. AM, BC, AA, BG, MP and KLG were responsible for analysis and interpretation of data. All authors contributed to drafting the article, revising it critically for important intellectual content and had final approval of the version to be published. 


\section{REFERENCES}

1. Chornokur G, Amankwah EK, Schildkraut JM, Phelan CM. Global ovarian cancer health disparities. Gynecol Oncol. 2013;129(1):258-264.

doi:10.1016/j.ygyno.2012.12.016

2. Rosenthal ET, Evans B, Kidd J, Brown K, Gorringe H, van Orman M, et al. Increased Identification of Candidates for High-Risk Breast Cancer Screening Through Expanded Genetic Testing. J Am Coll Radiol. 2017;14(4):561-568. doi:10.1016/j.jacr.2016.10.003

3. Castro E, Goh C, Olmos D, Saunders E, Leongamornlert D, Tymrakiewicz M, et al. Germline BRCA mutations are associated with higher risk of nodal involvement, distant metastasis, and poor survival outcomes in prostate cancer. J Clin Oncol. 2013;31(14):1748-1757. doi:10.1200/JCO.2012.43.1882

4. Cavanagh H, Rogers KMA. The role of BRCA1 and BRCA2 mutations in prostate, pancreatic and stomach cancers. Hered Cancer Clin Pract. 2015;13(1):1-7. doi:10.1186/s13053-015-0038-X

5. Stoppa-Lyonnet D. The biological effects and clinical implications of BRCA mutations: Where do we go from here? Eur J Hum Genet. 2016;24(S1):S3-S9. doi:10.1038/ejhg.2016.93

6. Hartmann LC, Lindor NM. The Role of Risk-Reducing Surgery in Hereditary Breast and Ovarian Cancer. $N$ Engl J Med. 2016;374(5):454-468. doi:10.1056/NEJMra1503523

7. Paluch-Shimon S, Cardoso F, Sessa C, Balmana J, Cardoso MJ, Gilbert F, et al. Prevention and screening in BRCA mutation carriers and other breast/ovarian hereditary cancer syndromes: ESMO clinical practice guidelines for cancer prevention and screening. Ann Oncol. 2016;27(Supplement 5):v103-v110. doi:10.1093/annonc/mdw327

8. National Breast Cancer Foundation Inc. Genetic testing for breast cancer.

9. Yurgelun MB, Hiller E, Garber JE. Population-wide screening for germline BRCA1 and 
BRCA2 mutations: Too much of a good thing? J Clin Oncol. 2015;33(28):3092-3095. doi:10.1200/JCO.2015.60.8596

10. Mahon SM. Cancer Risks for Men With BRCA1/2 Mutations. Oncol Nurs Forum. 2014;41(1):99-101. doi:10.1007/s10689

11. Rauscher EA, Dean M. "I've just never gotten around to doing it": Men's approaches to managing BRCA-related cancer risks. Patient Educ Couns. 2018;101:340-345.

12. NICE. Familial Breast Cancer: Classification and Care of People at Risk of Familial Breast Cancer and Management of Breast Cancer and Related Risks in People with a Family History of Breast Cancer. Clinical Guideline 164. London; 2013.

13. Evans JP, Skrzynia C, Burke W. The complexities of predictive genetic testing. BMJ. 2001;322(7293):1052-1056. doi:10.1136/bmj.322.7293.1052

14. Gabai-Kapara E, Lahad A, Kaufman B, Friedman E, Segev S, Renbaum P, et al. Population-based screening for breast and ovarian cancer risk due to BRCA1 and BRCA2. Proc Natl Acad Sci. 2014;111(39):14205-14210. doi:10.1073/pnas.1415979111

15. Sayani A. Inequities in genetic testing for hereditary breast cancer: implications for public health practice. J Community Genet. 2018;(ii):1-5. doi:10.1007/s12687-018-03708

16. Holloway SM, Bernhard B, Campbell H, Cetnarskyj R, Lam WWK. Inequality of use of Cancer Genetics Services by members of breast, ovarian and colorectal cancer families in South East Scotland. Fam Cancer. 2008;7(3):259-264. doi:10.1007/s10689-0089184-x

17. Cragun DF associated with genetic counseling and B testing in a population-based sample of young B women with breast cancer, Bonner D, Akbari MR, et al. Factors associated with genetic counseling and BRCA testing in a population-based sample of young Black women with breast cancer. Breast Cancer Res Treat. 2015;151(1):169-176. 
doi:10.1007/s10549-015-3374-7

18. Yusuf RA, Rogith D, Hovick SRA, Peterson SK, Burton-Chase AM, Fellman BM,. et al. Attitudes toward molecular testing for personalized cancer therapy. Cancer. 2015;121(2):243-250. doi:10.1002/cncr.28966

19. Mai PL, Vadaparampil ST, Breen N, McNeel TS, Wideroff L, Graubard BI. Awareness of cancer susceptibility genetic testing: The 2000, 2005, and 2010 national health interview surveys. Am J Prev Med. 2014;46(5):440-448.

doi:10.1016/j.amepre.2014.01.002

20. Finney Rutten LJ, Gollust SE, Naveed S, Moser RP. Increasing public awareness of direct-to-consumer genetic tests: Health care access, internet use, and population density correlates. J Cancer Epidemiol. 2012;2012:6-10. doi:10.1155/2012/309109

21. Heck JE, Franco R, Jurkowski JM, Sheinfeld Gorin S. Awareness of genetic testing for cancer among United States hispanics: The role of acculturation. Community Genet. 2008;11(1):36-42. doi:10.1159/000111638

22. Butrick M, Kelly S, Peshkin BN, Luta G, Nusbaum R, Hooker GW, et al. Uptake of BRCA1/2 Genetic Testing in a Randomized Trial of Telephone Counseling. Genet Med. 2015;17(6):467-475. doi:10.1038/gim.2014.125.Uptake

23. Pagan J, Su D, Li L, Armstrong K, Asch DA. Racial and Ethnic Disparities in Awareness of Genetic Testing for Cancer Risk. Am J Prev Med. 2009;37(6):524-530. doi:10.1016/j.amepre.2009.07.021

24. Molster C, Charles T, Samanek A, O’Leary P. Australian study on public knowledge of human genetics and health. Public Health Genomics. 2009;12(2):84-91. doi:10.1159/000164684

25. Haga SB, O’Daniel JM, Tindall GM, Lipkus IR, Agans R. Survey of U.S. Public Attitudes Towards Pharmacogenetic Testing. Pharmacogenomics J. 2012;12(3):197- 
204. doi:10.1530/ERC-14-0411.Persistent

26. Whitehead M. The concepts and principles of equity and health. Health Promot Int. 1991;6(3):217-228. doi:10.1093/heapro/6.3.217

27. Department for Communities and Local Government. The English Index of Multiple Deprivation (IMD) 2015 - Guidance.; 2015. https://www.gov.uk/government/sta tistics/english-indices-ofdeprivation-2015. (Accessed 2 May 2020).

28. Klein J, Moeschberger M. Survival Analysis: Techniques for Censored and Truncated Data. Second. (Springer, ed.). New York; 2003.

29. Hess KR. Graphical methods for assessing violations of the proportional hazards assumption in cox regression. Stat Med. 1995;14(15):1707-1723. doi:10.1002/sim.4780141510

30. Sterne JAC, White IR, Carlin JB, Spratt M, Royston P, Kenward MG, et al. Multiple imputation for missing data in epidemiological and clinical research: potential and pitfalls. BMJ. 2009;338:b2393. doi:10.1136/bmj.b2393

31. D'Andrea E, Marzuillo C, De Vito C, Di Marco M, Pitini E, Vacchio MR, et al. Which BRCA genetic testing programs are ready for implementation in health care? A systematic review of economic evaluations. Genet Med. 2016;18(12):1171-1180. doi:10.1038/gim.2016.29

32. Singh K, Lester J, Karlan B, Bresee C, Geva T, Gordon O. Impact of family history on choosing risk-reducing surgery among BRCA mutation carriers. Am J Obstet Gynecol. 2013;208(4):329.e1-329.e6. doi:10.1016/j.ajog.2013.01.026

33. Metcalfe K, Eisen A, Senter L, Risch HA, Rosen B, Murphy J, et al. International trends in the uptake of cancer risk reduction strategies in women with a BRCA1 or BRCA2 mutation. Br J Cancer. 2019;121(1):15-21. doi:10.1038/s41416-019-0446-1

34. MacLeod R, Beach A, Henriques S, Knopp J, Nelson K, Kerzin-Storrar L. Experiences 
of predictive testing in young people at risk of Huntington's disease, familial cardiomyopathy or hereditary breast and ovarian cancer. Eur J Hum Genet. 2013;22:396. https://doi.org/10.1038/ejhg.2013.143.

35. Brunstrom K, Murray A, McAllister M. Experiences of Women Who Underwent Predictive BRCA 1/2 Mutation Testing Before the Age of 30. J Genet Couns. 2016;25(1):90-100. doi:10.1007/s10897-015-9845-5

36. Healey E, Taylor N, Greening S, Wakefield CE, Warwick L, Williams R, et al. Quantifying family dissemination and identifying barriers to communication of risk information in Australian BRCA families. Genet Med. 2017;19(12):1323-1331. doi:10.1038/gim.2017.52

37. Fehniger J, Lin F, Beattie MS, Joseph G, Kaplan C. Family communication of BRCA1/2 results and family uptake of BRCA1/2 testing in a diverse population of BRCA1/2 carriers. J Genet Couns. 2013;22(5):603-612. doi:10.1007/s10897-013-9592-4

38. Cheung EL, Olson AD, Yu TM, Han PZ, Beattie MS. Communication of BRCA Results and Family Testing in 1,103 High-Risk Women. Cancer Epidemiol Biomarkers \&amp;amp; Prev. 2010;19(9):2211 LP - 2219. doi:10.1158/1055-9965.EPI-10-0325

39. Lieberman S, Lahad A, Tomer A, Koka S, BenUziyahu M, Raz A, et al. Familial communication and cascade testing among relatives of BRCA population screening participants. Genet Med. 2018;20(11):1446-1454. doi:10.1038/gim.2018.26

40. Menko FH, ter Stege JA, van der Kolk LE, Jeanson KN, Schats W, Moha DA, et al. The uptake of presymptomatic genetic testing in hereditary breast-ovarian cancer and Lynch syndrome: a systematic review of the literature and implications for clinical practice. Fam Cancer. 2019;18(1):127-135. doi:10.1007/s10689-018-0089-z

41. Sermijn E, Delesie L, Deschepper E, Pauwels I, Bonduelle M, Teugels E, et al. The impact of an interventional counselling procedure in families with a BRCA1/2 gene 
mutation: efficacy and safety. Fam Cancer. 2016;15(2):155-162. doi:10.1007/s10689$015-9854-4$

42. Black L, McClellan KA, Avard D, Knoppers BM. Intrafamilial disclosure of risk for hereditary breast and ovarian cancer: points to consider. J Community Genet. 2013;4(2):203-214. doi:10.1007/s12687-012-0132-y

43. George R, Kovak K, Cox SL. Aligning Policy to Promote Cascade Genetic Screening for Prevention and Early Diagnosis of Heritable Diseases. J Genet Couns. 2015;24(3):388-399. doi:10.1007/s10897-014-9805-5

44. Mitchell C, Goodwin D, Ploem C, Bell J, Hennekam R, Wallace S, et al. Exploring the potential duty of care in clinical genomics under UK law. Med Law Int. 2017;17(3):158182. doi:10.1177/0968533217721966

45. Rothstein MA. Reconsidering the duty to warn genetically at-risk relatives. Genet Med. 2018;20(3):285-290. doi:10.1038/gim.2017.257

46. Dheensa S, Lucassen A, Fenwick A. Limitations and Pitfalls of Using Family Letters to Communicate Genetic Risk: a Qualitative Study with Patients and Healthcare Professionals. J Genet Couns. 2018;27(3):689-701. doi:10.1007/s10897-017-0164-x

47. King M-C, Lahad A, Levy-Lahad E. Proposed shift in screening for breast cancer--reply. JAMA. 2015;313(5):525-526. doi:10.1001/jama.2014.17442

48. King M-C, Levy-Lahad E, Lahad A. Population-based screening for BRCA1 and BRCA2: 2014 Lasker Award. JAMA. 2014;312(11):1091-1092. doi:10.1001/jama.2014.12483 


\section{SUPPLEMENTAL MATERIAL}

Figure 1 - Time to predictive $B R C A$ testing
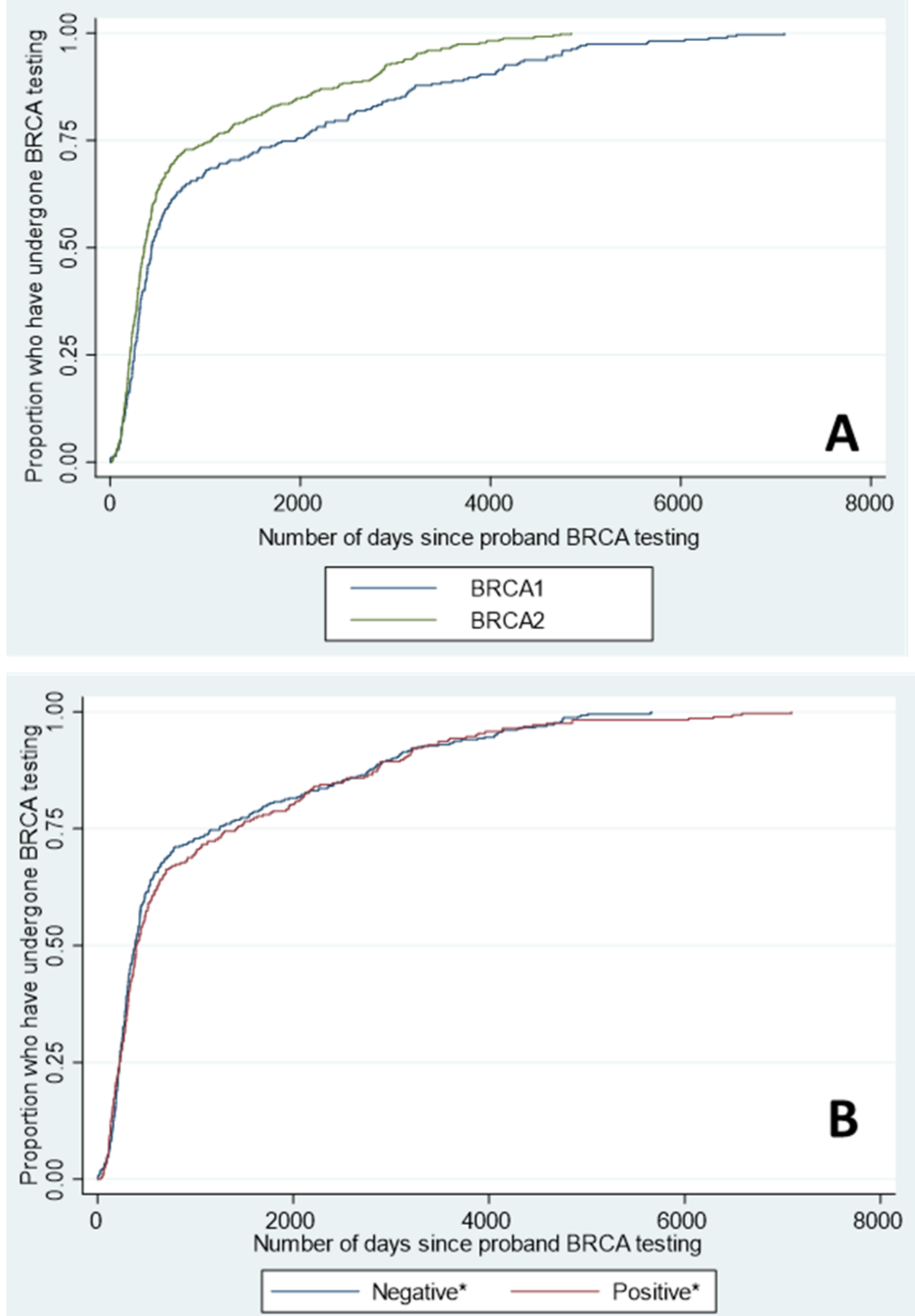

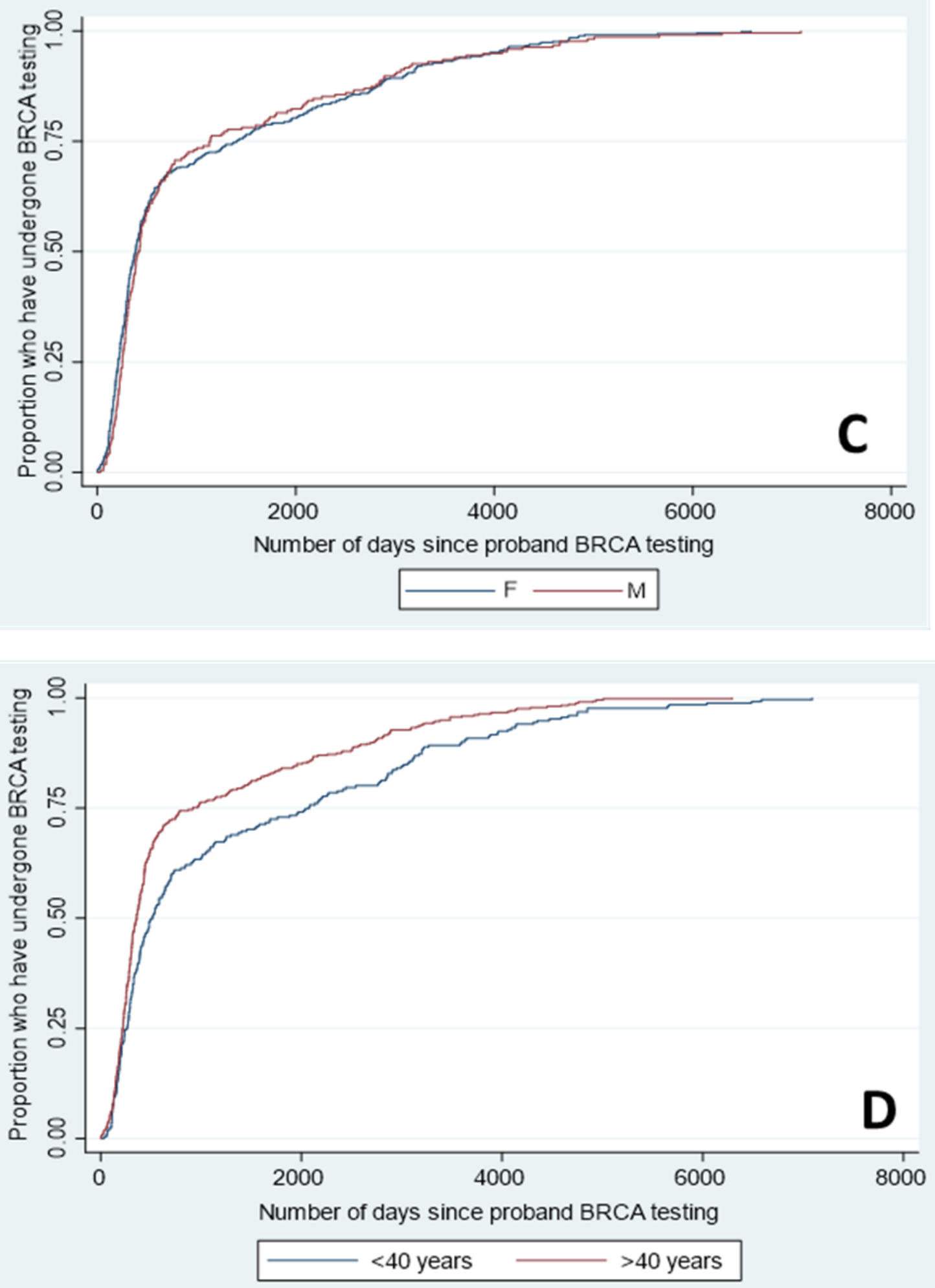


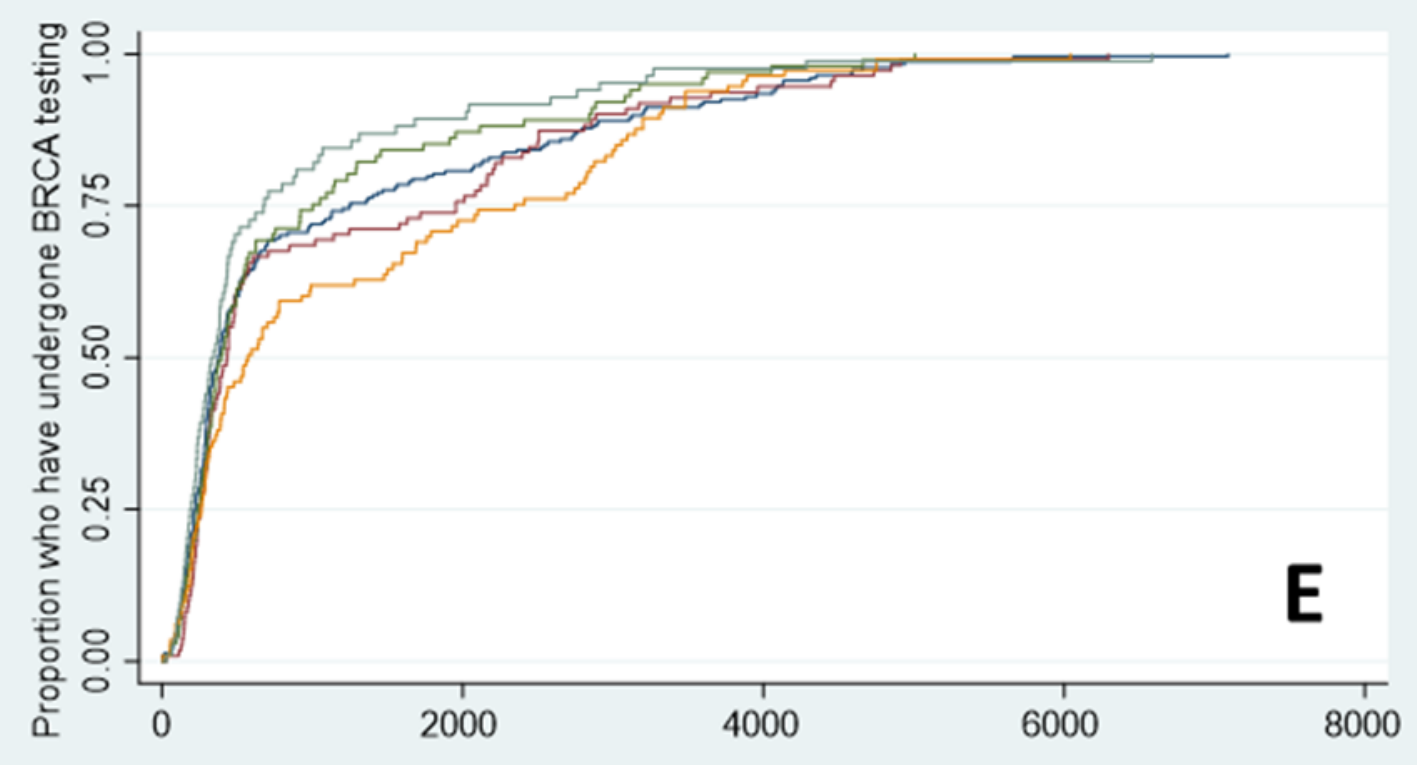

Number of days since proband BRCA testing

$\begin{array}{rr}\longrightarrow \text { IMDQ }=1 & \text { IMDQ }=2 \\ \text { IMDQ }=3 & \\ \text { IMDQ }=5 & \end{array}$

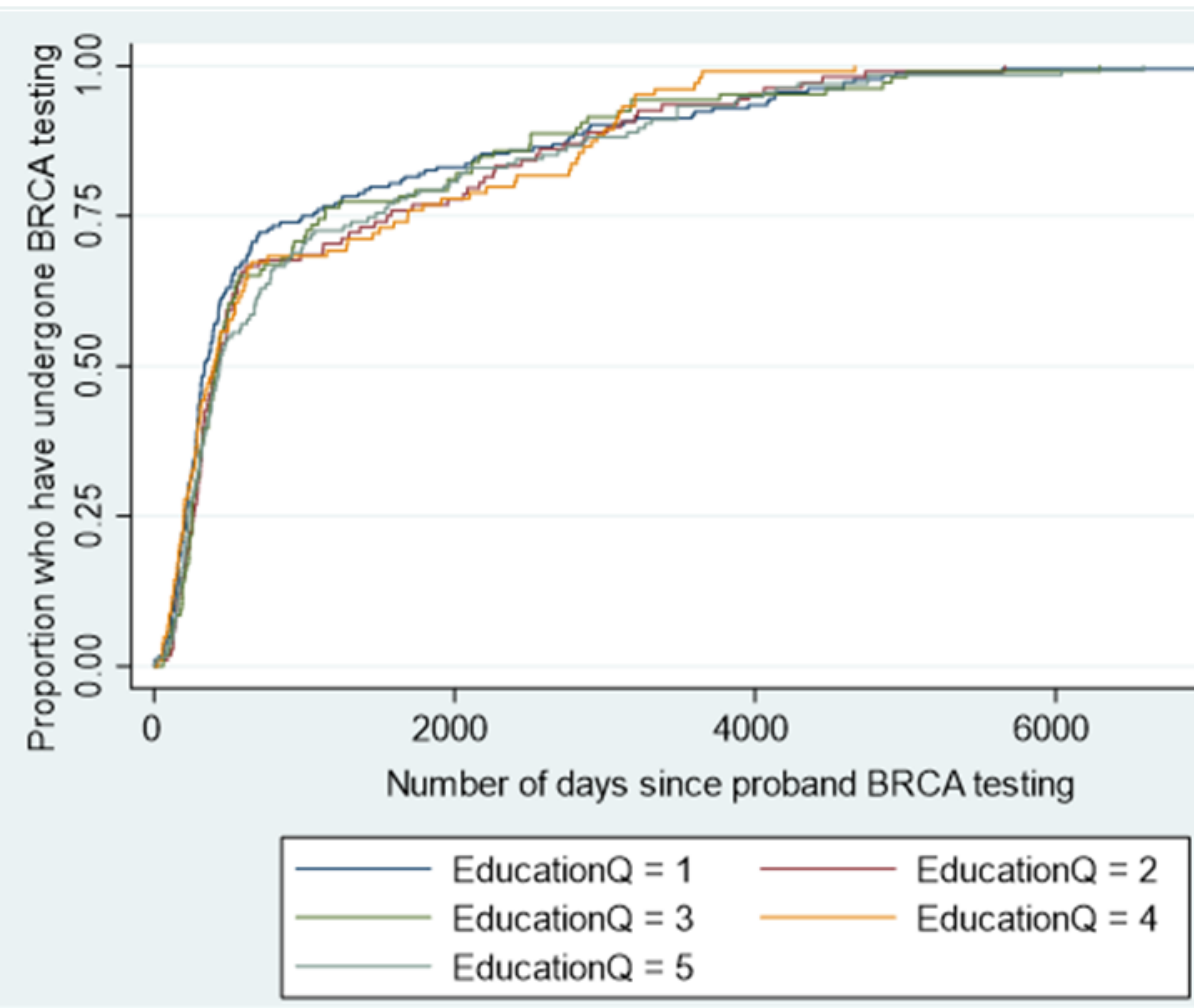

(A) Time to predictive $B R C A$ testing for $B R C A 1 / 2$ (B) Time to predictive $B R C A$ testing by gender. (C) Time to predictive $B R C A$ testing by $B R C A$ gene tested. (D) Time to predictive $B R C A$ testing age group. (E) Time to predictive $B R C A$ testing by Index of Multiple Deprivation (IMD). (F) Time to predictive $B R C A$ testing by education and skills quintile. 